University of Nebraska - Lincoln

DigitalCommons@University of Nebraska - Lincoln

May 2000

\title{
SELECTIVE AREA CHEMICAL VAPOR DEPOSITION OF CHROMIUM OXIDES
}

\author{
Ruihua Cheng \\ University of Nebraska-Lincoln
}

C.N. Borca

University of Nebraska-Lincoln

Peter A. Dowben

University of Nebraska-Lincoln, pdowben@unl.edu

Follow this and additional works at: https://digitalcommons.unl.edu/physicsdowben

Part of the Physics Commons

Cheng, Ruihua; Borca, C.N.; and Dowben, Peter A., "SELECTIVE AREA CHEMICAL VAPOR DEPOSITION OF CHROMIUM OXIDES" (2000). Peter Dowben Publications. 166.

https://digitalcommons.unl.edu/physicsdowben/166

This Article is brought to you for free and open access by the Research Papers in Physics and Astronomy at DigitalCommons@University of Nebraska - Lincoln. It has been accepted for inclusion in Peter Dowben Publications by an authorized administrator of DigitalCommons@University of Nebraska - Lincoln. 


\title{
SELECTIVE AREA CHEMICAL VAPOR DEPOSITION OF CHROMIUM OXIDES
}

\author{
Ruihua Cheng, C.N. Borca, and P.A. Dowben
}

Department of Physics and Astronomy and the Center for Materials Research and Analysis (CMRA), Behlen Laboratory of Physics, University of Nebraska-Lincoln, NE 68588-0111, USA, pdowben@unlserve.unl.edu

\begin{abstract}
We demonstrate that two-phase $\mathrm{CrO}_{2}$ and $\mathrm{Cr}_{2} \mathrm{O}_{3}$ thin films can be grown by using selective organometallic chemical vapor deposition through the oxidation of $\mathrm{Cr}(\mathrm{CO})_{6}$ in an oxygen environment. While the magnetization measurements show that both chromium oxides are present, the relative weight of each phase depends on the oxygen partial pressure. Changes of the Curie temperature, $\mathrm{T}_{\mathrm{c}}$, and the saturation magnetization field may be possible by controlling the stoichiometry.
\end{abstract}

\section{INTRODUCTION}

Chromium oxides have been seriously considered as spin-polarized electron injectors to spin-tunnel junctions [1] and other magnetoresistive devices [2,3]. The insulating antiferromagnetic chromium oxide $\mathrm{Cr}_{2} \mathrm{O}_{3}$ has a Neél temperature of $307 \mathrm{~K}$ and is suitable as a tunnel junction barrier [3] both below and above the Neél temperature. The ferromagnetic chromium oxide $\mathrm{CrO}_{2}$ with $\mathrm{T}_{\mathrm{c}}$ of 397k [4], has been predicted half-metallic (metallic for one spin direction while insulating for the other spin direction) by band structure calculations [5-9], though Kulatov and Mazin found $\mathrm{CrO}_{2}$ to be insulating in both spin directions [10]. Evidence of nearly $100 \%$ polarization, consistent with the half metallic character of $\mathrm{CrO}_{2}$, were observed in spin-polarized photoemission [11], vacuum tunneling [12], and Andreev scattering [13], though some discrepancies from perfect half metallic character remain unresolved. The high electron polarization, in addition to the half metallic character of the surface [9] (and by extension, one hopes the interface as well) makes $\mathrm{CrO}_{2}$ an attractive material for spin-polarized electron tunneling, and very large tunneling magnetoresistance (TMR) is expected.

It is difficult to fabricate $\mathrm{CrO}_{2}$ films using conventional methods because $\mathrm{CrO}_{2}$ is metastable. This is not altogether bad, as the two-phase $\mathrm{CrO}_{2} / \mathrm{Cr}_{2} \mathrm{O}_{3}$ system exhibits higher magnetoresistance than the pure material [3]. The oxidation of the organometallic complex hexacarbonyl $\mathrm{Cr}(\mathrm{CO})_{6}$ has the potential for selective deposition of $\mathrm{CrO}_{2}$ [14-17]. These studies have established that chromium oxides are the thermodynamic sinks of chromium hexacorbonyl decomposition [16], and the oxidation is further aided by the presence of an ambient oxygen background $[14,15]$. By modifying this organometallic chemical vapor deposition (OMCVD) procedure, we have been able to fabricate the ferromagnetic and antiferromagnetic chromium oxides. Here we describe both the growth and the magnetic properties of these films.

\section{EXPERIMENTAL APPROACH}

Film growth was carried out on Si (111) substrates in an ultra high vacuum chamber with maintained base pressure of $1.0^{-9}$ Torr. This chamber was designed for laser-initiated chemical vapor deposition, as described elsewhere [18-19]. The prevalent source compound was $\mathrm{Cr}(\mathrm{CO})_{6}$. 
During the deposition the photolytic decomposition of $\mathrm{Cr}(\mathrm{CO})_{6}$ was performed by a commercial nitrogen laser with the main emission line at $337 \mathrm{~nm}$ (corresponding to $3.69 \mathrm{eV}$ ) and running at a repetition rate of $10 \mathrm{~Hz}$. A quartz lens was used to focus the radiation onto the substrate.

The laser-initiated decomposition and oxidation was aided by the ambient oxygen $\left(\mathrm{O}_{2}\right)$ atmosphere ranging from $2 \times 10^{-7}$ to $1 \times 10^{-6}$ Torr, relative to the $\mathrm{Cr}(\mathrm{CO})_{6}$ partial pressure of $1 \times 10^{-5}$ Torr. Purity of the gases introduced was monitored with a quadruple mass spectrometer operated in pulse counting mode.

The films were examined by scanning electron microscopy (SEM) and x-ray emission spectroscopy (XES or EDAX). Magnetic measurements have been carried out by using a superconducting quantum interference device (SQUID) magnetometer.

\section{RESULTS}

Figure 1 shows the SEM image of the film fabricated with $1 \times 10^{-6} \mathrm{Torr}_{2}$ partial pressure and $1 \times 10^{-5} \operatorname{Torr} \operatorname{Cr}(\mathrm{CO})_{6}$ partial pressure. The topology of the film is relatively uniform, with only a fine microstructure visible on an $800 \mathrm{~nm}$ scale.

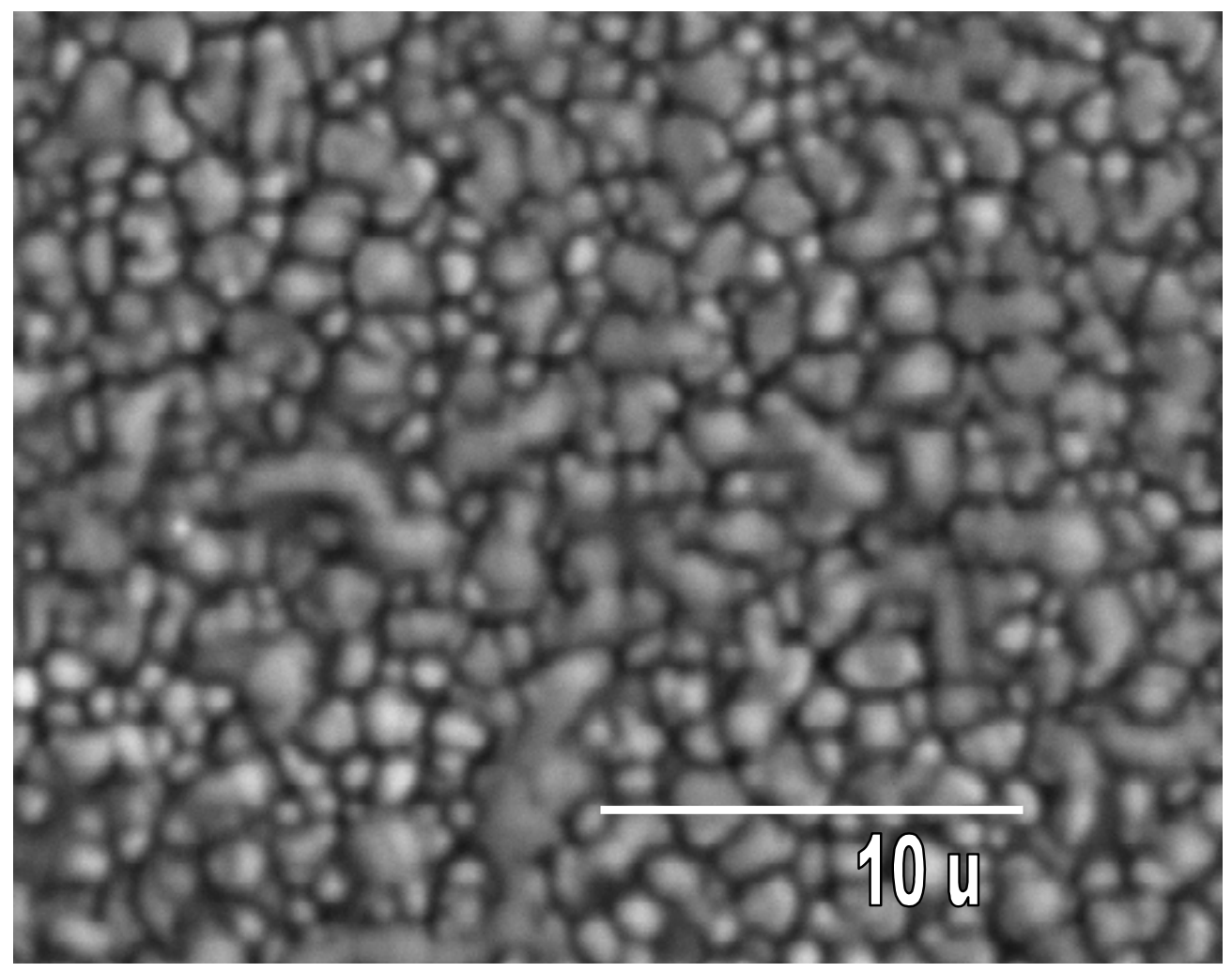

Figure 1: The scanning electron microscope image of a chromium oxide film fabricated on a Si (111) substrate by laser-initiated decomposition of $\mathrm{Cr}(\mathrm{CO})_{6}$ (pressure $1 \times 10^{-5}$ Torr) in an ambient $\mathrm{O}_{2}\left(1 \times 10^{-6}\right.$ Torr) background. 


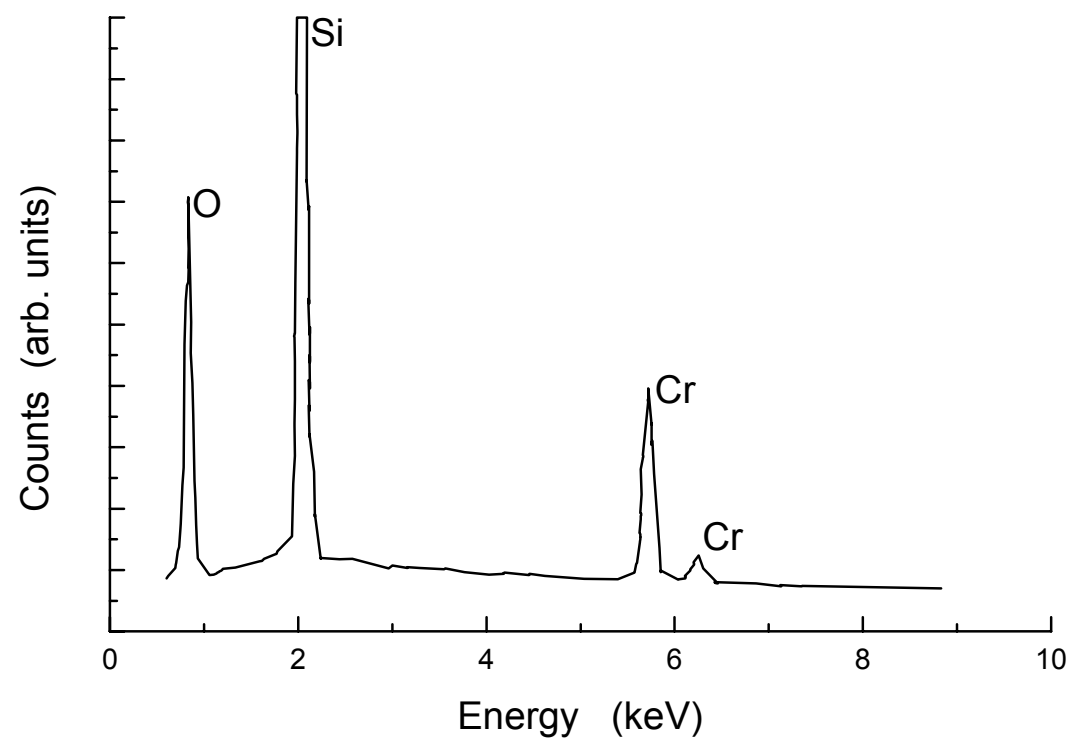

Figure 2: The EDAX spectra of the film shown in Figure 1. Note the strong oxygen and chromium signals in addition to the silicon signal from the $\mathrm{Si}(111)$ substrate.

As seen in Figure 2, the EDAX spectra of the same film shown in Figure 1, provides evidence for the desirable oxygen and chromium signal in addition to the strong Si signal from the substrate.

Figure 3 shows the magnetization versus temperature obtained from SQUID. The critical temperature clearly depends upon the oxygen partial pressure at the time of film fabrication. At low oxygen partial pressure (an $\mathrm{O}_{2}$ pressure of $2 \times 10^{-7}$ Torr relative to the $\mathrm{Cr}(\mathrm{CO})_{6}$ partial pressure of $1 \times 10^{-5}$ Torr) the Curie temperature was $345 \pm 10 \mathrm{~K}$. At higher oxygen partial pressure (an $\mathrm{O}_{2}$ pressure of $1 \times 10^{-6}$ Torr relative to the $\mathrm{Cr}(\mathrm{CO})_{6}$ partial pressure of $1 \times 10^{-5}$ Torr) the Curie temperature was $390 \pm 10 \mathrm{~K}$.

The hysteresis loop, shown in the inset to Figure 3, was obtained at $100 \mathrm{~K}$ with the applied magnetic field in the plane of the film. The curve shown is for the sample with the lower $\mathrm{O}_{2}$ partial pressure (an $\mathrm{O}_{2}$ pressure of $2 \times 10^{-7}$ Torr relative to the $\mathrm{Cr}(\mathrm{CO})_{6}$ partial pressure of $1 \times 10^{-5}$ Torr). We find that the saturation field for this film is about $1.5 \mathrm{~T}$.

\section{DISCUSSION}

The absence of a sharp $T_{c}$ and the presence of a long tail in the magnetization curves (Figure 3) near the critical temperature, are suggestive of a two-phase system. This is supported by indications of both ferromagnetic and antiferromagnetic behavior in the hysteresis loops.

The fact that the coercive fields for these films are often not symmetric in our films suggests uniaxial antiferromagnetism, in addition to the more conventional antiferromagnetic behavior. In the hysteresis loop obtained for the film at the lower oxygen partial pressure, for the left half of the loop the coercivity is 250 Oe while for the right half of the loop the coercivity is $150 \mathrm{Oe}$, in addition to having other characteristics of antiferromagnetism: strong hysteresis at higher fields. 


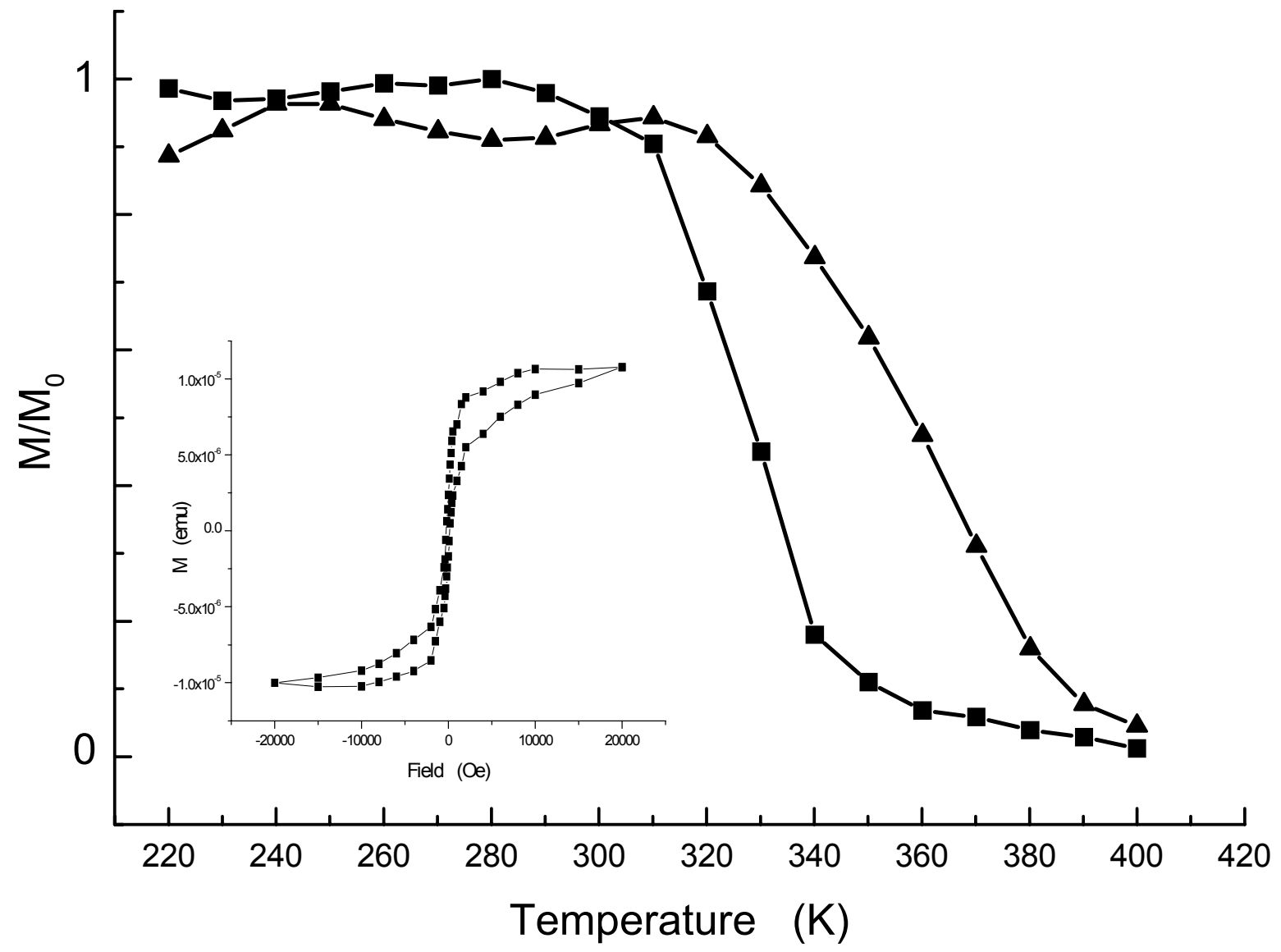

Figure 3: The magnetization $\left(\mathrm{M} / \mathrm{M}_{0}\right)$ versus temperature $(\mathrm{T})$ at an applied field of $\mathrm{H}=500$ Oe. Data are shown for two films: at low oxygen partial pressure $(\mathbf{A})$, i.e. $\left(\right.$ an $_{2}$ pressure of $2 \times 10^{-7}$ Torr relative to the $\mathrm{Cr}(\mathrm{CO})_{6}$ partial pressure of $1 \times 10^{-5}$ Torr) and at higher oxygen partial pressure $(\square)$, i.e. (an $\mathrm{O}_{2}$ pressure of $1 \times 10^{-6}$ Torr relative to the $\mathrm{Cr}(\mathrm{CO})_{6}$ partial pressure of $1 \times 10^{-5}$ Torr). The hysteresis loop, shown as an inset, was taken at $100 \mathrm{~K}$ for the film with an $\mathrm{O}_{2}$ pressure of $2 \times 10^{-7}$ Torr.

We believe that our films contain both ferromagnetic $\mathrm{CrO}_{2}$ and antiferromagnetic $\mathrm{Cr}_{2} \mathrm{O}_{3}$ phases. At lower oxygen partial pressures, $\mathrm{CrO}_{2}$ becomes less dominant, compared with $\mathrm{Cr}_{2} \mathrm{O}_{3}$, and the Curie temperature is suppressed to lower temperatures than the expected $397 \mathrm{~K}$ of $\mathrm{CrO}_{2}$ (the Neél temperature of $\mathrm{Cr}_{2} \mathrm{O}_{3}$ is $307 \mathrm{~K}$ ). When we increased the $\mathrm{O}_{2}$ partial pressure, the amount of $\mathrm{CrO}_{2}$ phase increased, and the critical temperature approached the expected $\mathrm{T}_{\mathrm{c}}$ of $397 \mathrm{~K}$.

In any case, deposition of our two-phase chromium oxide films is restricted to the area of the substrate illuminated with the light, so that the process is clearly a selective area deposition process. 


\section{CONCLUSIONS}

We have used laser-assisted chemical vapor deposition and oxidation of $\mathrm{Cr}(\mathrm{CO})_{6}$ to make chromium oxide thin films. The advantage of this technique is selective area deposition. The resulting films exhibit behavior consistent with a two-phase system containing both $\mathrm{Cr}_{2} \mathrm{O}_{3}$ and $\mathrm{CrO}_{2}$ domains in the films, and the relative weight of each phase appears to depend on the $\mathrm{O}_{2}$ partial pressure. If we choose the appropriate oxygen partial pressure, we should be able to obtain pure $\mathrm{Cr}_{2} \mathrm{O}_{3}$ and $\mathrm{CrO}_{2}$ phases respectively.

\section{ACKNOWLEDGEMENTS}

This work was supported by NSF through grant \# DMR-98-02126, the Center for Materials Research and Analysis (CMRA) and the Nebraska Research Initiative at the University of Nebraska.

\section{BIBLIOGRAPHY}

1. A.M. Bratkovsky, Phys. Rev. B. 56 (1997) p. 2344.

2. S.S. Manoharan, D. Elefant, G. Reiss and J.B. Goodenough, Appl. Phys. Lett. 72 (1998) p. 984; X.W. Li, A. Gupta, T.R. McGuire, P.R. Duncombe, and Gang Xiao, J. Appl. Phys. 85 (1999) p. 5585; K. Suzuki and P.M. Tedrow, Phys. Rev. B. 58 (1998) p. 11597.

3. J.D.M. Coey, A.E. Berkowitz, Ll Balcells, F.F. Putris and A. Barry, Phys. Rev. Lett. 80 (1998) p. 3815.

4. J. S. Kouvel and D. S. Rodbell, J. Appl. Phys. 38 (1967) p. 979.

5. K. Schwarz, J. Phys. 16 (1986) p. L211.

6. S. Matar, G. Demazeau, J. Sticht, V. Eyert, and J. Kübler, J. de Physique I 2 (1992) p. 315.

7. M.A. Korotin, V.I. Anisimov, D.I. Khomskii and G.A. Sawatzky, Phys. Rev. Lett. 80 (1998) p.4305.

8. S.P. Lewis, P.B. Allen, T. Sasaki, Phy. Rev. B 55 (1997) p. 10253.

9. H. van Lueken and R.A. de Groot, Phys. Rev. B 51 (1995) p. 7176.

10. E. Kulatov and I.I. Mazin, J. Phys. Condens. Matter, 2 (1990) p. 343.

11. K.P. Kämper, W. Schmitt, G. Güntherodt, R.J. Gambino, and R. Ruf. Phys. Rev. Lett., 59 (1987) p. 2788.

12. R. Weisendanger, H.-J. Güntherodt, G. Güntherodt, R.J. Gambino, and R. Ruf. Phys. Rev. Lett., 65 (1990) p. 247.

13. R.J. Soulen, et al., Science, 282 (1998) p. 85; R.J. Soulen, M.S. Osofsky, B. Nadgorny, T. Ambrose, P. Boussard, S.F. Cheng, C.T. Tanaka, J. Nowack, J.S. Moodera, G. Laprade, A. Barry and M.D. Coey, J. Appl. Phys., 85 (1999) p. 4589.

14. P. A. Dowben, Yoon Gi Kim, S. Baral-tosh, G. O. Ramseyer, Chanyong Hwang and M. Onellion, J. Appl. Phys., 67 (1990) p. 5658.

15. K. Perkins, C. Hwang, M. Onellion, Yoon-Gi Kim, and P.A. Dowben, Thin Solid Films 198 (1991) p. 317-329.

16. D.C. Mancini, S. Varma, J.K. Simons, R.A. Rosenberg, and P.A. Dowben, J. Vac. Sci. Technol. B8 (1990) p.1804-1807. 
17. P.A. Dowben and M. Onellion, "Fabrication of $\mathrm{CrO}_{2}$ and Cobalt Doped $\mathrm{CrO}_{2}$ Films from Organometallic Complexes", U.S. Patent Number 4,980,198 issued December 25, 1990.

18. D. Welipitiya, C. N. Borca, P. A. Dowben, I. Gobulukoglu, H. Jiang, B. W. Robertson and J.D. Zhang, Mat. Res. Soc. Symp. Proc., 475 (1997) p. 257.

19. C. N. Borca, D. Welipitiya, S. Adenwalla and P. A. Dowben, Phys. Low-Dim. Struct., 11/12 (1997) p.173. 